\title{
Practicing physicists' knowledge about disability: Development of the Disability and Physics Careers Survey (DPCS)
}

\author{
Erin Scanlon \\ Physics Department, University of Central Florida, 4111 Libra Drive, Orlando, Florida, 32825 \\ Dan Oleynik, Jacquelyn J. Chini \\ Physics Department, University of Central Florida, 4111 Libra Drive, Orlando, Florida, 32825
}

\begin{abstract}
Previous research indicated that physics instructors receive little training about supporting people with disabilities, physics curricular materials are not designed to support students with disabilities, and STEM professionals hold more negative views about people with disabilities than their peers in other academic disciplines. We argue that if physics mentors do not know about disability and physics careers, then they will be less likely to appropriately mentor students with disabilities. The purpose of this paper is to introduce, discuss the development of, and present pilot study findings for the Disability and Physics Careers Survey (DPCS), which measures practicing physicists' knowledge about disability and beliefs about the viability of physics career for people with a range of abilities. We collected pilot data at 9 meetings and through a physics listserv; overall 208 participants completed the DPCS. We found that practicing physicists have knowledge about hearing, visual, and emotional/mental health impairments (but not other impairments) and believe the viability of physics careers varies by impairment type.
\end{abstract}




\section{INTRODUCTION}

People with disabilities enroll in postsecondary education in increasing rates [1,2] and they represent approximately $20 \%$ of the postsecondary student body [2] People with disabilities also enroll in science and engineering majors at comparable rates to their peers without disabilities (28.0\% and 27.6\%, respectively) [2]. However, people with disabilities only represent $9.3 \%$ of employed physical scientists [2]. Thus, people with disabilities are interested in pursuing STEM majors and careers, but do not matriculate or join the workforce at rates similar to their peers without disabilities. Additionally, multiple studies show that postsecondary faculty lack awareness of the legal requirements related to accommodations [3-4], state that they do not feel prepared to teach students with disabilities [5,6] and want more training related to accessibility [7]. STEM professionals have also been shown to hold more negative views about disability than their peers in other disciplines $[6,8]$.

One possible reason for the underrepresentation of people with disabilities in the STEM workforce is related to the knowledge and beliefs about disability of practicing physicists [9-11]. Specifically, Ruhindwa, Randall, and Cartmel (2016) state "people with disabilities often experience exclusion from participating in mainstream employment due to environmental, attitudinal, social and organizational barriers, and not issues relating to the effects of their impairments" (p. 6) [12]. If physics mentors have inaccurate knowledge or negative beliefs about people with disabilities, then they are less likely to appropriately mentor students and colleagues with disabilities. For example, if a physics mentor believes that astrophysics requires the use of sight, then they will be less likely to encourage or support a student with a visual impairment to pursue a career as an astrophysicist.

The purpose of this paper is to describe the development of the Disability and Physics Careers Survey (DPCS), which will allow us to investigate research questions about practicing physicists' knowledge about disability and beliefs about the viability of physics careers for people with a variety of abilities. We also present preliminary data related to these research questions collected through a pilot implementation of the survey.

\section{DISABILITY AND PHYSICS CAREERS SURVEY}

The DPCS is a multi-part survey intended for use with practicing physicists. Section $I$ is intended to measure participants' knowledge about disability diagnoses. Participants identify which disability diagnoses belong in a given list of categories of impairment (i.e., group of impairments and/or diagnoses that have similar characteristics and/or affect the same part of the body). The exemplar diagnoses were identified through interviews with physics experts (described in Sec. IIIB) and based on the representation of diagnoses in the STEM community [2]. The categories of impairment are a combination of categories from similar previous studies [13], literature about characterizing dimensions of ability [14], and categories used by the National Science Foundation (NSF) [2]. The most appropriate category of impairment for each diagnosis was defined by the literature base.

Section II explores participants' beliefs about the viability of physics careers for people with a variety of abilities. Participants list physics careers that would be viable and not viable for people with a variety of diagnoses (that were either provided by the participants or provided to the participants depending on the iteration of the survey). As we have previously discussed, disability is an incomplete description of ability that is steeped in ableist cultural norms [14]; however, it is difficult to describe what we mean by "normal ability" [15]. Thus, we used diagnoses to describe the range of abilities.

Section III consists of demographic questions about the participants, including gender, race/ethnicity, age, and career. Additionally, this section includes questions about the participants' disability-specific background, including prior disability or accessibility training, personal experiences with disability (e.g., personal disability status, friends/family with disabilities), and approximate number of students with disabilities they have taught or worked with.

\section{SURVEY DEVELOPMENT PROCESS}

The DPCS was developed iteratively in a multiple phase process: 1) initial drafting of the survey, 2) interviews with practicing physicists, 3) pilot implementation of the survey and iterative revisions.

\section{A. Initial DPCS development}

During the initial development phase, the research team referenced a similar study from geosciences by Atchison and Libarkin [13] to develop the career and demographic questions. In their study, Atchison and Libarkin gave participants a category of impairment and asked the participants to list geoscience careers that were viable for people with that impairment [13]. We added section I to investigate if physicists have similar conceptions of categories of impairment to support the validity of our findings and asked about non-viable careers.

\section{B. Interviews with practicing physicists}

During the second phase, we interviewed practicing physicists (4 physics graduate students, 1 postdoctoral scholar, and 2 faculty members) about the survey. The purpose of these hour-long, semi-structured interviews was to investigate participants' thoughts while taking the survey and to investigate its validity and reliability. Our initial intention was to use findings from the interviews to create 
closed-ended versions of the first two sections of the DPCS. However, the interview participants experienced difficulties in naming diagnoses and physics careers. So, we added a list of diagnoses in section I. We also made the questions in section II open-ended and asked participants to list the diagnosis they had in mind as well as the viable and not viable physics careers.

The interview participants also made distinctions about the viability of physics careers based on the severity of the impairment. This is likely related to the way the categories of impairment were written at the time; for example, one category of impairment was "severe mobility impairment." Our intention was not to include severity as an added level of nuance in participants' responses, so we removed the severity from all labels for the categories of impairment. We also added a "health" category of impairment based on the interview participants' responses.

\section{Pilot study and iterative revision}

\section{Pilot data collection}

After revising the survey based on the interview findings, we piloted the survey by having practicing physicists complete the survey. We recruited practicing physicists to complete the DPCS at 8 American Physical Society (APS) meetings (including 6 section meetings and 2 division meetings), a non-APS but STEM-specific meeting, and through a physics-specific topical listserv. All meeting participants were eligible to complete two surveys (see Ref. [14] for discussion of the other survey), and the DPCS was given first at the division meetings. All meeting participants (including students, faculty and industry members) were eligible to complete the survey and received a $\$ 5$ gift card to compensate them for their time. The first author of this paper (E.S.) collected the pilot data and informally talked with survey participants about their thoughts about the survey. Table I includes the demographic information disaggregated by meeting for the 208 participants that completed the DPCS.

\section{Iterative survey revisions based on pilot data}

The post-interview revised version of the DPCS was given to participants at S1 and S2. Many participants remarked that the survey was too long and difficult; specifically, they said it was difficult to identify diagnoses and physics careers in Section II. For example, a participant responded "hearing test" when asked to name a hearing impairment diagnosis. So, we added a diagnosis for each category of impairment for section II as an example of the type of answers we were seeking and kept an open-ended response for participants to list a self-generated diagnosis.

This revised version of the DPCS was used by participants at three subsequent meetings (i.e., D1, S3, and S4). Participants at these meetings also said that the survey took too long to complete and that they did not know how to answer the questions. To again shorten the survey, we removed the fill in the blank diagnosis question from section II. Thus, revised section II included a single diagnosis provided to the participants for each category of impairment for which participants were to identify viable and non-viable physics careers. Also, multiple international practicing physicists said they did not know many of the words used in the survey, including the diagnoses. To aid in understanding the disability-specific vocabulary, we added hover-text (i.e., a description that appears when you mouse over a word or phrase) that included definitions for: diagnosis, disability, and category of impairment. We did not include hover-text for the given diagnoses because the purpose of the survey is to determine participants' knowledge about disability.

Then participants at meetings D2 and M completed the revised survey. These participants indicated that the attention check (i.e., survey question that screens for participants who are not reading the questions) was confusing. The original version of the attention check was: "Attention Check (place in Unsure category)." Participants indicated that because they did not know what an attention was, they thought it was a diagnosis related to attention. Thus, we updated the attention check to be: "Select Unsure (this is to check your attention)." Finally, participants at meetings S5, LS, and S6 completed the revised survey.

Table I: Pilot study participant demographics listed in percent of respondents for each demographic category

\begin{tabular}{llllll}
\hline \hline Mtg & $\mathrm{N}$ & $\begin{array}{l}\text { Gender } \\
(\mathrm{M}, \mathrm{F}, \mathrm{N})\end{array}$ & $\begin{array}{l}\text { Race/ Ethnicity } \\
(\mathrm{W}, \mathrm{A}, \mathrm{H}, \mathrm{B}, \mathrm{N}, \mathrm{M})\end{array}$ & $\begin{array}{l}\text { Career } \\
(\mathrm{F}, \mathrm{S}, \mathrm{I}, \mathrm{G}, \mathrm{H})\end{array}$ & $\begin{array}{l}\text { Disability Experience } \\
(\mathrm{N}, \mathrm{T}, \mathrm{F}, \mathrm{P})\end{array}$ \\
\hline S1 and S2 & 23 & $70,26,4$ & $78,9,13,0,0,0$ & $35,52,9,0,4$ & $22,48,61,17$ \\
D1, S3, and S4 & 37 & $46,49,3$ & $38,32,11,5,0,11$ & $16,68,5,3,0$ & $19,57,35,19$ \\
D2 and M & 88 & $72,25,1$ & $59,13,7,7,3,9$ & $25,40,9,10,0$ & $31,36,47,20$ \\
S5, LS, and S6 & 60 & $40,57,2$ & $62,10,3,3,0,8$ & $38,52,2,0,0$ & $15,71,48,27$ \\
\hline Total & 208 & $58,38,2$ & $58,15,7,5,1,8$ & $28,50,6,5,1$ & $23,51,47,22$ \\
\hline \hline
\end{tabular}

Table I includes the APS meeting where the participants were recruited ( $\mathrm{S}$ is section, D is division, LS is listserv, and M is the non-APS meeting), number of participants $(\mathrm{N})$, gender ( $\mathrm{M}$ is male, $\mathrm{F}$ is female, and $\mathrm{N}$ is non-binary), race/ethnicity (W is white, $\mathrm{A}$ is Asian, $\mathrm{H}$ is Hispanic/Latino/a, B is Black, $\mathrm{N}$ is American Indian/Alaskan Native, and M is multiple), career (F is faculty, $\mathrm{S}$ is student, $\mathrm{I}$ is industry, $\mathrm{G}$ is government job, and $\mathrm{H}$ is high school teacher), and disability experience ( $\mathrm{N}$ is no experience, $\mathrm{T}$ is taught or worked with a student with a disability, $\mathrm{F}$ is family, friend, or personal contact with a disability, and $\mathrm{P}$ is personal disability). Demographics are listed in percent. 
Table II: Common incorrectly categorized diagnoses (grey shading indicates the literature defined category of impairment)

\begin{tabular}{lrrrrrrrrr}
\hline \hline Diagnosis & Hearing & Visual & $\begin{array}{l}\text { Learning/ } \\
\text { Reading }\end{array}$ & Cognitive & Health & Physical & Mobility & $\begin{array}{l}\text { Mental } \\
\text { Health }\end{array}$ & Unsure \\
\hline Tinnitus & $53.4 \%$ & $0.5 \%$ & $0 \%$ & $0.5 \%$ & $2.4 \%$ & $10.6 \%$ & $2.8 \%$ & $1.0 \%$ & $27.9 \%$ \\
Dyslexia & $0.5 \%$ & $8.7 \%$ & $72.1 \%$ & $8.0 \%$ & $1.0 \%$ & $0.5 \%$ & $0.5 \%$ & $1.9 \%$ & $7.2 \%$ \\
Processing Disorder & $0.5 \%$ & $0 \%$ & $27.4 \%$ & $49.5 \%$ & $0 \%$ & $0 \%$ & $0.5 \%$ & $6.7 \%$ & $15.4 \%$ \\
Dysgraphia & $0 \%$ & $4.3 \%$ & $17.8 \%$ & $2.9 \%$ & $0.5 \%$ & $1.9 \%$ & $1.0 \%$ & $0.5 \%$ & $71.2 \%$ \\
Autism Spectrum Disorder & $0.5 \%$ & $2.9 \%$ & $10.1 \%$ & $44.2 \%$ & $1.0 \%$ & $1.0 \%$ & $1.4 \%$ & $18.8 \%$ & $20.2 \%$ \\
ADHD & $0 \%$ & $0 \%$ & $40.9 \%$ & $32.2 \%$ & $1.9 \%$ & $1.0 \%$ & $0.5 \%$ & $17.3 \%$ & $6.3 \%$ \\
Down Syndrome & $0 \%$ & $0 \%$ & $9.6 \%$ & $53.8 \%$ & $6.3 \%$ & $10.6 \%$ & $0.5 \%$ & $6.7 \%$ & $12.5 \%$ \\
Migraines & $0 \%$ & $3.8 \%$ & $3.4 \%$ & $9.1 \%$ & $38.9 \%$ & $33.1 \%$ & $0 \%$ & $3.8 \%$ & $7.7 \%$ \\
Irritable Bowel Syndrome & $0 \%$ & $0 \%$ & $0.5 \%$ & $0.5 \%$ & $41.3 \%$ & $45.7 \%$ & $1.0 \%$ & $2.4 \%$ & $8.7 \%$ \\
Amyotrophic lateral sclerosis & $0.5 \%$ & $0 \%$ & $0 \%$ & $1.0 \%$ & $11.5 \%$ & $37.0 \%$ & $18.3 \%$ & $1.0 \%$ & $30.8 \%$ \\
Multiple Sclerosis & $0 \%$ & $0.5 \%$ & $0 \%$ & $1.0 \%$ & $16.3 \%$ & $49.5 \%$ & $9.6 \%$ & $1.4 \%$ & $21.6 \%$ \\
Arthritis & $0 \%$ & $0 \%$ & $0.5 \%$ & $0 \%$ & $4.8 \%$ & $66.3 \%$ & $26.0 \%$ & $0 \%$ & $2.4 \%$ \\
Scoliosis & $0 \%$ & $0 \%$ & $0 \%$ & $0.5 \%$ & $4.3 \%$ & $65.4 \%$ & $10.6 \%$ & $0.5 \%$ & $18.8 \%$ \\
Carpal Tunnel & $0.5 \%$ & $1.0 \%$ & $0.5 \%$ & $0 \%$ & $4.3 \%$ & $63.9 \%$ & $13.9 \%$ & $0.5 \%$ & $15.4 \%$ \\
Amputated Limb & $0 \%$ & $0 \%$ & $0 \%$ & $0 \%$ & $1.9 \%$ & $50.0 \%$ & $42.8 \%$ & $0 \%$ & $5.3 \%$ \\
Cerebral Palsy & $0 \%$ & $0 \%$ & $0 \%$ & $9.1 \%$ & $8.7 \%$ & $38.9 \%$ & $17.3 \%$ & $3.8 \%$ & $22.1 \%$ \\
Paraplegia & $0 \%$ & $0 \%$ & $0 \%$ & $0 \%$ & $2.4 \%$ & $27.4 \%$ & $41.3 \%$ & $0.5 \%$ & $28.4 \%$ \\
\hline \hline
\end{tabular}

\section{PILOT STUDY FINDINGS AND DISCUSSION}

\section{A. Section I: Diagnoses and Categories of Impairment}

Pilot study participants were commonly aligned with the most appropriate category (i.e., more than $80 \%$ of participants' responses were correct) for the hearing (partial deafness: $95.7 \%$, deafness: $97.6 \%$ ), visual (blindness: 91.3\%, color blindness: $95.2 \%$, partial blindness: $96.6 \%$ ), and emotional/mental health (depression: $92.8 \%$, posttraumatic stress disorder: $88.0 \%$, bipolar disorder: $80.3 \%$, anxiety: $93.8 \%$, borderline personality disorder: $81.7 \%$ ) categories of impairment. This indicates that participants understand the variety of diagnoses within the hearing, visual, and emotional/mental health categories of impairment.

Table II includes the percent of pilot study participants' responses in each category of impairment for diagnoses that were commonly placed incorrectly. In this table, the grey shading represents the correct category of impairment for each diagnosis. In general, participants incorrectly placed diagnoses that belong in the learning/reading (dyslexia, processing disorder, dysgraphia), cognitive (autism spectrum disorder, attention deficit/hyperactivity disorder, down syndrome), health (migraines, irritable bowel syndrome, amyotrophic lateral sclerosis, multiple sclerosis), physical (arthritis, scoliosis, carpal tunnel), and mobility (amputated limb, cerebral palsy, paraplegia) categories of impairment.

Participants' responses for the health, physical, and mobility categories of impairment commonly overlapped. For example, for multiple sclerosis $16.3 \%$ of participants placed the diagnosis in the literature-defined health category while $49.5 \%$ placed it in the physical category and $9.6 \%$ placed it in the mobility category. In our original conception of the categories of impairment (also called dimensions of ability) [14], we combined the physical and mobility categories. Taking participants' responses into account, we combined the physical and mobility categories in the final version of the survey.

Similarly, there was also overlap in participants' responses to the learning/reading and cognitive categories of impairment (e.g., processing disorder, ADHD). In the final version of the DPCS, we combined these two categories of impairment due to participants' responses and because learning/reading impairments can be classified as a type of cognitive impairment. The overlap in responses between the cognitive and learning/reading categories combined with the fact that people with ADHD and autism spectrum disorder (which are cognitive impairments) are enrolling in postsecondary education at increasing rates $[1,16,17]$ implies we may not be best serving people with these impairments. Additionally, in the final version of the survey we shortened the list of diagnoses that participants place into categories of impairment. We did this to shorten the survey and also to focus on diagnoses that participants would most frequently encounter in the physics community.

\section{B. Section II: Diagnoses and Physics Careers}

Table III includes pilot study participants' responses for viable physics careers. Because the survey was continually revised, the layout and specific wording for Section II 
Table III: Common viable physics career responses disaggregated by category of impairment

\begin{tabular}{lrrrrrrrr}
\hline \hline Physics Career & Hearing & Visual & $\begin{array}{l}\text { Learning/ } \\
\text { Reading }\end{array}$ & Cognitive & Health & Physical & Mobility & $\begin{array}{l}\text { Mental } \\
\text { Health }\end{array}$ \\
\hline Total Responses & 435 & 380 & 363 & 279 & 343 & 323 & 369 & 359 \\
\hline Teacher & 30 & 37 & 18 & 8 & 23 & 26 & 34 & 18 \\
Professor & 24 & 27 & 25 & 6 & 24 & 30 & 31 & 14 \\
Engineer & 10 & 6 & 9 & 4 & 9 & 7 & 8 & 9 \\
Data Analyst & 14 & 11 & 8 & 6 & 6 & 3 & 9 & 6 \\
Theory Research & 28 & 28 & 10 & 9 & 18 & 17 & 22 & 13 \\
Experiment Research & 26 & 12 & 18 & 15 & 12 & 12 & 14 & 11 \\
Computation Research & 17 & 13 & 3 & 1 & 2 & 5 & 5 & 4 \\
Science Communicator & 7 & 7 & 7 & 3 & 6 & 4 & 6 & 8 \\
Government Sector & 5 & 3 & 2 & 2 & 2 & 2 & 3 & 3 \\
Private Industry Sector & 15 & 12 & 10 & 8 & 10 & 8 & 11 & 9 \\
\hline
\end{tabular}

questions changed. However, across each version we consistently asked participants to identify viable and nonviable physics careers. The data presented in Table III is preliminary and has been aggregated across all distributions of the survey as well as collapsed into categories of impairment (i.e., in the $\mathrm{S} 1$ version participants generated a diagnosis while in the S5 version participants were given a diagnosis; all responses were collapsed along the category of impairment). The data in the Total Responses row includes the total number of careers that participants responded (i.e., if a participant wrote: "teacher, government, engineer", this consisted of three responses). The physics careers in Table III are the most common responses listed by participants, excluding responses such as all/any, most, and unsure (which constituted $16.6 \%, 2.3 \%$, and $2.5 \%$, respectively for the hearing category of impairment, as a representative example) and other miscellaneous responses including noncareers (e.g., "yes"), non-physics specific careers (e.g., "patent law"), and non-responses (e.g., "?"). Thus, the number of total responses is higher than the sum of the number of responses for each career category.

The cognitive category of impairment had the lowest raw number of responses across all categories of impairment (279). This could imply that practicing physicists know the least about the cognitive category of impairment (aligned with the common incorrect responses from Section I findings) or could imply that participants think there are many fewer viable physics careers for people with cognitive impairments. However, since the survey was open-ended a non-response does not necessarily mean disagreement with the viability of a career.

Looking across categories of impairment, a career as a physics professor was more frequently listed as viable for the physical and mobility categories of impairment but less frequently for the cognitive and emotional/mental health categories. This is not a surprising result as Stephen Hawking is a well-known successful physicist with a physical/mobility impairment. If there were more common stories of well-known physics professors with cognitive and emotional/mental impairments, then maybe practicing physicists would more frequently say that a physics professor career would be viable for them. It is also important that these stories do not promote the idea that only people with disabilities who are 'uniquely brilliant' can meaningfully participate in physics [18]. Similarly, theory research was less frequently listed as viable for the learning/reading, cognitive, and emotional/mental health categories but more frequently for the visual, hearing, and mobility categories. Again, this result is not surprising because there are common conceptions that theoretical physics research is "just thinking." So, if a person has an impairment that affects their thinking, then physicists may think they cannot do theoretical physics research.

\section{SUMMARY AND NEXT STEPS}

Overall, participants' responses indicate that practicing physicists understand the variety of diagnoses within the hearing, visual, and emotional/mental health categories of impairment but not others. Additionally, participants' beliefs about the viability of physics careers varied by category of impairment.

There are many additional trends to be analyzed with this data set (e.g., viable careers within a category of impairment, comparing viable and non-viable careers across categories of impairment). In the future, we plan to continue our examination of these data as well as to collect additional data. We also plan to interview practicing physicists to gather rich data about their thoughts about the survey, its relationship with the original survey [13], and disability more generally. Because practicing physicists' knowledge and beliefs about disability have direct impacts on who becomes part of the physics community via mentoring relationships, we plan to use our research findings in the development of professional development materials for practicing physicists.

\section{ACKNOWLEDGMENTS}

This work is supported by NSF HRD 1750515. 
[1] G. A. Scott, Higher education and disability: Education needs a coordinated approach to improve its assistance to schools in supporting students, Government Accountability Office, 10, 1 (2009).

[2] National Science Foundation, National Center for Science and Engineering Statistics, Women, Minorities, and Persons with Disabilities in Science and Engineering: 2019. Special Report NSF 19-304, (2019).

[3] A. R. Thompson, L. Bethea, and J. Turner, Faculty knowledge of disability laws in higher education: A survey, Rehab. Counsel. Bulletin 40, 166 (1997).

[4] D. Zhang, L. Landmark, A. Reber, H. Hsu, O. M. Kwok, and B. Benz, University faculty knowledge, beliefs, and practices in providing reasonable accommodations to students with disabilities, Remedial Spec. Educ. 41, 276 (2010).

[5] K. Q. Baker, K. Boland, and C. M. Nowik, A campus survey of faculty and student perceptions of persons with disabilities, J. Post. Educ. \& Dis. 25, 309 (2012).

[6] K. Norman, D. Caseau, and G. P. Stefanich, Teaching students with disabilities in inclusive science classrooms: Survey results, Sci. Educ. 82, 127 (1998).

[7] T. S. Love, N. Kreiser, E. Camargo, M. E. Grubbs, E. J. Kim, P. L. Burge, and S. M. Culver, STEM faculty experiences with students with disabilities at a land grant institution, J. Educ. Train. Stud. 3, 27.

[8] S. Rao, Faculty attitudes and students with disabilities in higher education: A literature review, Coll. Stud. J 38, 191 (2004).

[9] M. E. McLaughlin, M. P. Bell, and D. Y. Stringer, Stigma and acceptance of persons with disabilities: Understudied aspects of workforce diversity, Group \& Organ. Mgmt. 29, 302 (2004).

[10] R. T. Fraser, K. Johnson, J. Hebert, I. Ajzen, J. Copeland, P. Brown, and F. Chan, Understanding employers' hiring intensions in relation to qualified workers with disabilities: Preliminary findings, J. Occup. Rehab. 20, 420 (2010).

[11] A. Hogan, S. M. Kyaw-Myint, D. Harris, and H. Denronden, Workforce participation barriers for people with disability, Int. J. Dis. Mgmt. 7, 1 (2012).

[12] A. Ruhindwa, C. Randall, and J. Carmel, Exploring the challenges experienced by people with disabilities in the employment sector in Australia: Advocating for inclusive practice - a review of literature, J. Social Inclusion 7, 4 (2016).

[13] C. Atchison, and J. Libarkin, Professionally held perceptions about the accessibility of the geosciences, Geosphere 12, 1154 (2016).

[14] E. M. Scanlon and J. J. Chini, Ability profiles: A framework for conceptualizing dimensions of ability, 2018 PERC Proceedings [Washington, DC, August 1-2, 2018], edited by A. Traxler, Y. Cao, and S. Wolf, DOI: 10.1119/perc.2018.pr.Scanlon.

[15] D. Goodley, Disability Studies: An Interdisciplinary Approach, 2nd ed. (Sage Publications, London, 2017).

[16] National Center for Education Statistics, 1995-96 national postsecondary student aid study: 1996. Report NPSAS:96, (1996).

[17] National Center for Education Statistics, Profile of undergraduate students: 2011-2012. Report NCES 2014-167.
[18] A. Traxler, and J. Blue, Disability in physics: Learning from binary mistakes. In Physics Education and Gender: Identity as an Analytic Lens for Research, A. J. Gonsalves, and A. T. Danielsson (eds), (2020). 